\title{
CAPítTULO 9
}

\section{EFEITOS DO GLUTAMATO NO CÉREBRO}

Sonia Luz Albarracín C. Leonardo R. Lareo

\section{INTRODUÇ̄̃̃O}

A neurotransmissão no sistema nervoso central (SNC) é mediada por uma estreita interação entre os neurônios e a glia, especialmente, nas sinapses excitatórias nas quais o L-glutamato é o neurotransmissor predominante (Volterra \& Meldolesi, 2005). Assim, o glutamato está envolvido nas principais funções do cérebro, como são os processos cognitivos de aprendizagem, a consolidação da memória e o desenvolvimento da plasticidade sináptica, apesar da desregulação da homeostase do glutamato estar associada a diferentes distúrbios patológicos como a depressão, a esquizofrenia e algumas doenças neurodegenerativas, por provocar um desequilíbrio entre o glutamato sináptico e o glial (Billard, 2018; Bliim et al., 2019).

O glutamato, como neurotransmissor, é originado metabolicamente dos esqueletos de carbono da glicose e da glutamina que atravessam a barreira hematoencefálica (BBB). Portanto, requerem um permanente suprimento glial. Assim, tanto neurônios como astrócitos e oligodendrócitos manifestam uma "dependência" de substratos, os quais são sintetizados, capturados ou liberados nestes tipos de células. Esse mecanismo é conhecido como "compartimentalização celular", 
que neste contexto, favorece a funcionalidade de todos os processos associados à comunicação sináptica. Um exemplo disso constitui a glutamina que está presente tanto no plasma $(500-750 \mu \mathrm{M})$ como no líquido cefalorraquidiano (LCR) (Stanley \& Prusiner, 1981), sendo considerado um metabólito importante, visto que favorece a síntese de aminoácidos e, portanto, de proteínas. Adicionalmente, pode ser usada para a síntese de ATP e para aumentar o reservatório de precursores para a síntese de neurotransmissores como o aspartato, o glutamato e o ácido $\gamma$-amino butírico (GABA). Em contraste, o glutamato é menos abundante extracelularmente e a relação de concentrações de glutamato-glutamina, no plasma, é de $1 / 50$.

A concentração aproximada de glutamato no cérebro é da ordem de 5 a $10 \mathrm{mM}$ (Arrubla et al., 2017) e a da glutamina é de $7 \mathrm{mM}$, embora possa ser maior nos somas ou pericarions dos mesmos neurônios em que a concentração é da ordem de $38 \mathrm{mM}$, de acordo com estudos neuroquímicos e quantitativos ultraestruturais (Christensen \& Fonnum, 1991a). Essa diferença destaca a relação dinâmica entre a produção de glutamato a partir da glutamina como mecanismo fundamental para a fisiologia celular o qual é conhecido como ciclo glutamato-GABA-glutamina, sendo que no cérebro constitui um paradigma fundamental para entender o mecanismo de compartimentalização entre os neurônios e a glia (Welbourne et al., 2001; Simão et al., 2016).

A manutenção do reservatório de glutamato no cérebro constitui um ponto do qual dependem delicados mecanismos em nível celular e molecular. Assim, o glutamato pode ser submetido a diferentes processos metabólicos para síntese ou a degradação em diversas reações de transaminação e de desaminação oxidativa que favorecem a incorporação de esqueletos de carbono para a produção de ATP (Welbourne et al., 2001). Isso dá origem, no SNC, a uma grande variedade de metabólitos que incluem o $\alpha$-cetoglutarato, piroglutamato, ácido $\gamma$-amino butírico (GABA) e $\gamma$-glutamil peptídeos. Entretanto, a conversão de glutamina para a produção de glutamato é funcionalmente uma das mais importantes (Stanley \& Prusiner, 1981).

Assim, o glutamato contido no cérebro pode ser encontrado em quatro compartimentos diferentes: a) nos terminais glutamatérgicos (40\%); b) nos terminais GABAérgicos (10\%) onde é necessário como precursor do GABA; c) em astrócitos para a síntese de glutamina (30\%); e d) em um compartimento multicelular no qual é usado para metabolismo energético (20\%). Uma diminuição no glutamato disponível para manter a função das sinapses glutamatérgicas ou GABAérgicas poderia resultar em danos ao acoplamento de excitação/inibição, isto 
é, no balanço glutamato/GABA. De maneira semelhante, uma perda da função astrocítica que impeça a capacidade de metabolizar o reservatório extracelular de glutamato pode diminuir a capacidade de detoxificação de íons amônio $\left(\mathrm{NH}_{4}^{+}\right)$ (Cooper, 1993). Esses dois cenários demonstram que deve existir um delicado equilíbrio na dinâmica da atividade metabólica em cada um desses compartimentos que garanta a funcionalidade de cada sistema, visto que, se perturbado, pode desencadear inúmeras alterações e estados patológicos.

Assim sendo, o metabolismo do glutamato no cérebro considera dois aspectos fundamentais: o primeiro está relacionado ao controle da concentração extracelular do neurotransmissor no espaço sináptico, devido a que a hiperestimulação dos receptores ionotrópicos, especialmente do tipo NMDA (N-metil-D-aspartato), produz eventualmente dano neuronal, fenômeno conhecido como excitotoxicidade (Tanović \& Alfaro, 2006). O segundo aspecto vincula-se com o delicado balanço na produção de íons amônio $\left(\mathrm{NH}_{4}^{+}\right)$, cujos excessos também resultam em efeitos deletérios no SNC. Para manter esse fino mecanismo em condições ótimas, existem duas estratégias principais que permitem que o cérebro reduza esses riscos e previna o dano neural. A primeira é mediada pela barreira função seletiva da hematoencefálica $(\mathrm{BBB})$, que limita o transporte de glutamato do sangue ao cérebro e a segunda, é a estratégia de compartimentalização metabólica entre os neurônios e a glia. O presente capítulo aborda as principais características do mecanismo de compartimentalização celular.

\section{TERMINAIS GLUTAMATÉRGICOS}

A transmissão glutamatérgica tem sido descrita em diversas regiões do sistema nervoso, que incluem: conexões córtico-corticais ipsilaterais e contralaterais, projeções corticais até a amídala, tubérculo olfatório, o putâmen, núcleo caudado, tálamo, colículo superior e inferior, área tegmental, substância negra (ou substância nigra), núcleo vermelho e medula espinal. Adicionalmente, o córtex entorrinal o qual participa na neurobiologia do hipocampo, e em conexões que incluem o septum, subiculum, corpo mamilar e hipotálamo, assim como também o córtex visual, retina e cerebelo (Billard, 2018; Bliim et al., 2019). Sua escala de ação se encontra na ordem de milissegundos e a ativação dos receptores de glutamato desempenha um papel importante nas mudanças duradouras que envolvem o fenótipo neuronal e o desenvolvimento dos receptores no SNC. Visto que os padrões de atividade sináptica excitatória são requeridos para o controle delicado das conexões sinápticas e a geração de mapas topográficos nas redes neurais (Kalb \& Fox, 1997). 
Metabolicamente, o glutamato é proveniente da glicose, da glutamina e do lactato. A glicose e a glutamina atravessam a BBB e são utilizados por neurônios e astrócitos. Devido à grande demanda de energia, os neurônios oxidam totalmente à glicose, inicialmente no citosol com a produção de piruvato, posteriormente, este $\alpha$-ceto-ácido é transportado à matriz mitocondrial onde é descarboxilado e oxidado até acetil-coenzima A (Acetil-CoA) pela ação do complexo piruvato desidrogenase. Posteriormente, a Acetil-CoA e o oxaloacetato se condensam para iniciar o ciclo dos ácidos tricarboxílicos (CAT). Uma vez no ciclo, são formados diferentes intermediários, como citrato, $\alpha$-cetoglutarato, succinato, fumarato e malato, até que, finalmente, se regenera uma molécula de oxaloacetato. No fim, são produzidos $2 \mathrm{CO}_{2}$ e $1 \mathrm{ATP}, 3 \mathrm{NADH}^{+} \mathrm{H}^{+}$e $1 \mathrm{FADH}_{2}$ por cada Acetil-CoA que entra no ciclo (Magistretti \& Allaman, 2018).

No entanto, sob condições de alta atividade neuronal, foi demonstrado o papel do lactato derivado do glicogênio dos astrócitos e seu transporte para os neurônios onde é usado como substrato metabólico (Calì et al., 2019; Magistretti \& Allaman, 2018). Alguns estudos indicam que durante os processos de potenciação em longo prazo (PLP), responsáveis pelo aprendizado e formação da memória, nessas condições, o lactato é o metabólito energético preferido, mais do que a glicose (Magistretti \& Allaman, 2018).

Como neurotransmissor, o glutamato é acumulado em vesículas que contêm altas concentrações $(100 \mathrm{mM})$ e é liberado do terminal pré-sináptico por exocitose dependente de $\mathrm{Ca}^{+2}$. No terminal pós-sináptico os receptores de glutamato (GluR) são expressos em praticamente todas as células neuronais e interagem com o neurotransmissor. Essa família é composta por receptores metabotrópicos de glutamato (mGluR) e receptores ionotrópicos de glutamato (iGluR). Os IGluRs foram classificados em três populações diferentes, cada uma definida pela ativação seletiva com diferentes análogos estruturais do glutamato. Assim, a família iGluR é composta por receptores ativados pelo N-metil-D-aspartato (NMDA) dos quais a estrutura quaternária é conhecida, e os receptores ativados pelo $\alpha$-amino-3-hidroxi-5-metil-4-isoxazolepropionato (AMPA) e pelo ácido kaínico (KAIN). Os receptores iGluR neuronais possuem canais catiônicos seletivos associados, que permitem aumentar as correntes de influxo de $\mathrm{Ca}^{2+}$ e $\mathrm{Na}^{+}$, enquanto o $\mathrm{K}^{+}$eflui através do mesmo canal (Billard, 2018; Bliim et al., 2019; Chen \& Gouaux, 2019).

\section{TERMINAIS GABAÉRGICOS}

A enzima glutamato descarboxilase (GAD) (E.C. 4.1.1.15), converte o glutamato em GABA (ácido $\gamma$-amino butírico), o neurotransmissor cerebral com 
maior atividade inibitória. Os circuitos inibitórios são diversos, embora os aspectos da biologia celular envolvidos em sua operação não sejam totalmente compreendidos. Nesse sentido, a caracterização funcional de diferentes subtipos de neurônios inibitórios não tem sido suficiente para explicar como a neurotransmissão GABAérgica regula a atividade sináptica de maneira tão relevante. Vários mecanismos emergentes modulam a neurotransmissão GABAérgica dinamicamente a partir do terminal pré-sináptico ou do pós-sináptico. Nesse sentido, essas sinapses contribuem para o desenvolvimento e amadurecimento dos circuitos até atingir o equilíbrio de excitação/inibição. Além disso, as interações entre as vias celulares, a difusão lateral de proteínas entre sinapses e o transportador de cloreto funcionam nas sinapses excitatórias e inibitórias e facilitam as adaptações inibitórias das sinapses (Maffei et al., 2017).

Pesquisas em nível farmacológico, molecular e genético mostram que as sinapses GABAérgicas são fundamentais no desenvolvimento do cérebro e mediam processos de plasticidade sináptica (Fazzari et al., 2010). Foram descritas múltiplas funções durante o desenvolvimento das sinapses GABAérgicas, entre as quais se destacam: a modulação do posicionamento dos neurônios no tecido para conseguir a diferenciação das células, o estabelecimento da morfologia e a forma dos contatos sinápticos com outros neurônios, assim como, participar no refinamento das conexões para fazer parte da complexa rede de neurotransmissão.

Curiosamente, nos últimos anos tem sido relatado que neurônios na área tegmental ventral (ATV) e na habenula coliberam glutamato e GABA de maneira conjunta. Isso sugere um papel complexo na regulação desses neurônios durante a neurotransmissão nessas regiões específicas (Yoo et al., 2016; Zimmermann et al., 2015). Esses achados não são mais recentes, demonstram a importância de manter o acoplamento de excitação/inibição, o que demostra que essas duas atividades interdependentes favorecem o equilíbrio do qual dependem tanto a funcionalidade celular como a dos circuitos neuronais prevenindo os mecanismos de excitotoxicidade (Fazzari et al., 2010).

\section{COMPARTIMENTO GLIAL}

As células gliais do SNC (astrócitos tipo I e II e oligodendrócitos) cumprem funções essenciais, como a manutenção da homeostase iônica (especialmente de potássio), compartimentalização metabólica, regulação da inflamação, secreção de moléculas tróficas e servir de guia e apoio à migração de neurônios durante o desenvolvimento do sistema nervoso. Além disso, exercem uma atividade 
moduladora sobre a comunicação neuronal ao eliminar neurotransmissores, prover seus precursores e manter concentrações no meio extracelular, permitindo a proteção dos neurônios contra a neurotoxicidade pelo excesso de glutamato e amônio $\left(\mathrm{NH}_{4}^{+}\right)$(Albrecht et al., 2007).

As células gliais, durante muito tempo, foram consideradas células não excitáveis e, portanto, de papel secundário nos processos de neurotransmissão. No entanto, vários estudos realizados desde os anos 2000 motivaram o reconhecimento de seu papel principal na funcionalidade do SNC. Assim, novos conceitos como "gliotransmissão" foram cunhados, um processo no qual moléculas são liberadas dos astrócitos para as células vizinhas, sendo induzidos sinais intra e extracelulares. Nesse sentido, se relatam também como "gliotransmissores" as moléculas envolvidas. Entretanto, os astrócitos não podem gerar potenciais de ação; o mecanismo excitatório está estabelecido quimicamente e é evidenciado por câmbios nas concentrações intracelulares de $\mathrm{Ca}^{+2}$, que são conhecidas como "oscilações de $\mathrm{Ca}^{+2}$ ", as quais se propagam de célula a célula, modulando a neurotransmissão (Bezzi \& Volterra, 2001; Volterra \& Meldolesi, 2005; Orellana \& Stehberg, 2014).

Recentemente, foi constatado que em diferentes sinapses, tanto no SNC como no sistema nervoso periférico (SNP), diversos neurotransmissores como glutamato, GABA, noradrenalina, acetilcolina, dopamina e adenosina estão implicados na ativação sináptica glial durante a neurotransmissão (Orellana \& Stehberg, 2014). Assim, por exemplo, os astrócitos do hipocampo expressam receptores específicos para glutamato, os quais, por mecanismos de sinalização mediados por hidrólise de fosfolipídios de membrana, geram inositol 1,4,5-trisfosfato (Ins1,4,5P3), favorecendo a elevação intracelular da concentração de $\mathrm{Ca}^{+2}$, e provocando "oscilações de $\mathrm{Ca}^{+2}$ " que se dispersam célula a célula através de uniões estreitas (Figura 9.1) (Mayorquin et al., 2018). A propagação dessas "ondas de $\mathrm{Ca}^{+2}$ " põe em evidência um mecanismo de sinalização glial que favorece as atividades de neuromodulação (Bezzi \& Volterra, 2001). Durante o disparo neuronal intenso, a liberação de neurotransmissores como glutamato e GABA induz elevações da concentração intracelular de cálcio $\left[\mathrm{Ca}^{2+}\right]_{i}$ nas células gliais, que por sua vez, provoca a liberação de moléculas que impactam a excitabilidade neuronal, a transmissão sináptica e a plasticidade (Bazargani \& Attwell, 2016). Adicionalmente, produto de outros tipos de sinais, a glia pode produzir "gliotransmissores" como NO, ATP, glutamato, prostaglandinas, entre outros, ou pode exercer funções de neuromodulação, como a liberação de moléculas como D-serina (Volterra \& Meldolesi, 2005). 


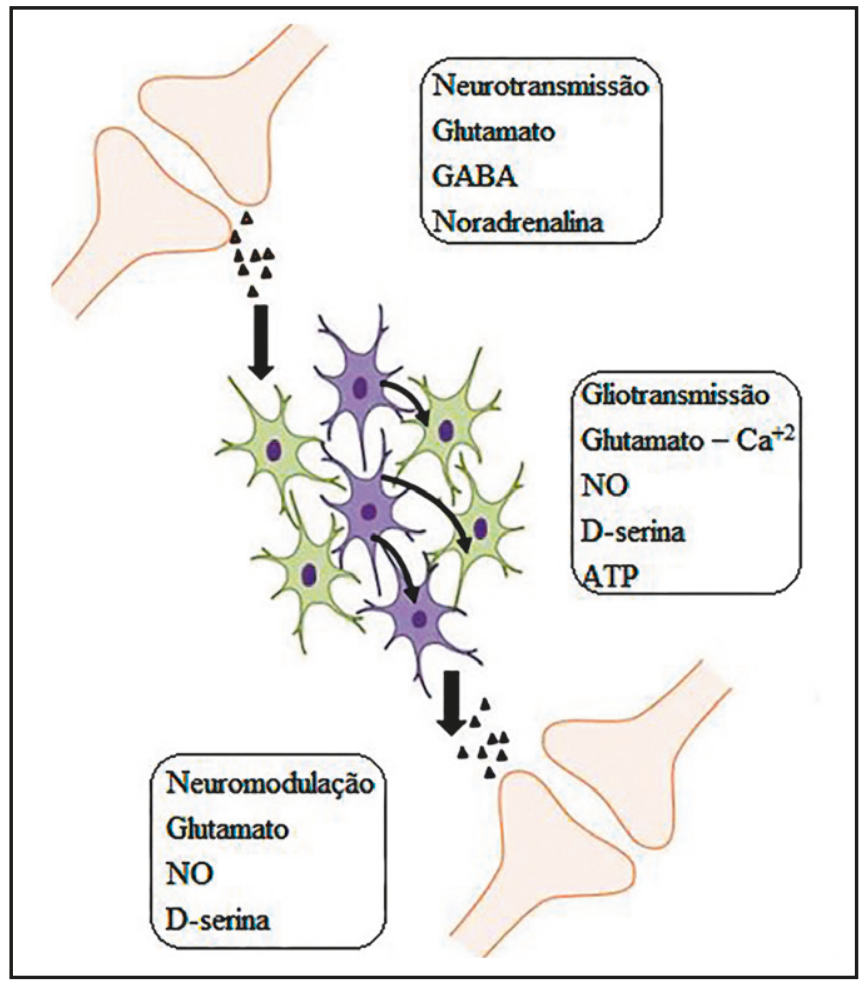

Figura 9.1 - Efeito neuromodulador de gliotransmissores por meio da sinalização mediada por ondas de cálcio através de uniões estreitas.

Fonte: figura adaptada de ppt- toolkit-Neuroscience: https://www.motifolio.com/neuroscience-all.html.

É assim que o mecanismo de gliotransmissão pode coordenar redes de neurônios e sinapses de uma região para outra. Devido a que os sinais de $\mathrm{Ca}^{2+}$ astrocíticos evocados localmente por sinapses ativas podem se expandir intracelularmente de sua fonte original para células diferentes, isso implica que o sinal viaja ao longo de processos astrocíticos e desencadeia a liberação de gliotransmissores em áreas distantes, regulando outras sinapses e circuitos distantes (Araque et al., 2014; Sahlender et al., 2014).

Tem sido relatado que os astrócitos envolvidos no mesmo circuito podem liberar diferentes tipos de gliotransmissores e, assim, modular a transmissão sináptica de múltiplas formas. No entanto, identificar o contexto dessas ações regulatórias e suas múltiplas respostas é um desafio na pesquisa em neurociência para tentar entender como elas operam sob condições fisiológicas (Araque et al., 2014). 


\section{SINAPSE TRIPARTITE}

Nos últimos anos, foi estabelecido o conceito de "sinapse tripartite", devido às múltiplas evidências que relatam a existência de uma regulação dinâmica e bidirecional da comunicação neuronal pelos astrócitos. O conceito representa uma visão funcional integrativa da fisiologia sináptica e considera os astrócitos como protagonistas ativos que regulam a transferência de informações entre os neurônios. De fato, o termo "sinapse tripartite" foi cunhado para enfatizar a modulação do espaço extracelular em torno das sinapses por astrócitos, independentemente da modulação ocorrer através da depuração dos transmissores sinápticos ou da entrega de compostos de sinalização para os loci sinápticos, extrasinápticos ou perisinápticos. Isso produz um mecanismo de retroalimentação, uma modulação homosináptica ou uma ação heterosináptica avançada, que poderia impactar os circuitos neurais (Araque et al., 2014; Farhy-Tselnicker \& Allen, 2018).

Nesse sentido, esse novo elemento da neurotransmissão favorece a modulação da comunicação entre os neurônios. Porém, a eficiência desse processo depende de dois fatores: a) da rápida liberação do neurotransmissor do neurônio pré-sináptico; e b) das baixas concentrações de neurotransmissores na sinapse Isso significa que estão envolvidos processos de síntese, liberação e recaptura do neurotransmissor para manter a eficiência do processo (Daikhin \& Yudkoff, 2000).

Tem sido relatado que a concentração do glutamato na sinapse é da ordem de 2-5 $\mu \mathrm{mol} / \mathrm{L}$ e pode se elevar depois da despolarização a um nível de 50-100 $\mu \mathrm{mol} / \mathrm{L}$. Assim, o glutamato deve ser removido rapidamente da sinapse empregando-se três sistemas: a) sequestro por neurônios pós-sinápticos; b) sequestro por neurônios pré-sinápticos; e c) remoção por astrócitos na "sinapse tripartite" (Daikhin \& Yudkoff, 2000). Esses três sistemas englobam mecanismos de compartimentalização metabólica para o glutamato que evidenciam a participação ativa de uma grande família de transportadores de alta afinidade para neurotransmissores excitatórios (EAAT). EAAT-1 e EAAT-2 expressam-se em astrócitos em grandes áreas do cérebro como lóbulo frontal, córtex e hipocampo. Ou seja, essas zonas particularmente ativas em sinapses glutamatérgicas contam com um efetivo sistema de remoção de glutamato. EAAT-3 se expressa em terminais nervosos, porém não é considerado um mecanismo importante de transporte de glutamato. EAAT-4 é um transportador neuronal limitado a células de purkinje e EAAT-5 se expressa na retina (Hayashi, 2018). 
Da mesma forma e através do mecanismo de compartimentação nas sinapses inibitórias, o GABA é capturado e metabolizado em astrócitos, graças à presença de transportadores eficientes de alta afinidade (Sellstrom \& Hamberger, 1977; Ramaharobandro et al., 1982). Nesse sentido, foram descritos quatro transportadores de alta afinidade para o GABA: GAT-1, GAT-3, GAT-B e XT1, todos dependentes de $\mathrm{Na}^{+} / \mathrm{Cl}^{-}$, associados às terminações nervosas do $\mathrm{SNC}$ ou associados às células gliais (Mestikawy et al., 1994). Sob condições normais, a concentração intraglial de GABA é de, aproximadamente, $1 \mathrm{mM}$ enquanto que a concentração extracelular é de $1 \mu \mathrm{M}$. Isso significa que essas células retiram ativamente o excesso de GABA (Sellstrom \& Hamberger, 1977). Parece ser que a afinidade do transportador do GABA depende da maturação do cérebro, tanto nos neurônios quanto na glia. $\mathrm{O}$ valor da constante de afinidade $\left(\mathrm{K}_{\mathrm{M}}\right)$ do transportador do GABA é de 5,5 $\mu \mathrm{M}$ em neurônios e $13 \mu \mathrm{M}$ em astrócitos (González, 1985).

Embora se pensasse que o transportador neuronal do GABA estivesse localizado exclusivamente nas terminações axonais, foi demonstrado que esse transportador também é encontrado no pericário neuronal. Tanto nos neurônios como nos astrócitos, o aumento das concentrações extracelulares de potássio estimula a liberação de GABA ao meio, o que estabelece um modelo bidirecional para o transportador de GABA. A absorção ideal de GABA requer concentrações intra e extracelulares de sódio e potássio as quais dependem do potencial de membrana (Sellstrom \& Hamberger, 1977; Christensen \& Fonnum, 1991b).

\section{CICLO GLUTAMATO-GABA-GLUTAMINA NO CÉREBRO}

Neste paradigma de sinapse tripartite, o ciclo glutamato-GABA-glutamina se torna importante. Esse ciclo promove a remoção rápida de glutamato e GABA das sinapses, mantendo uma baixa concentração de neurotransmissores e transformando essas moléculas em um substrato não neuroativo, a glutamina. (Sidoryk-Wegrzynowicz \& Aschner, 2013; Simão et al., 2016; Hertz \& Rothman, 2017; Hayashi, 2018). Ou seja, os astrócitos servem como "transportadores" de glutamato e GABA de volta aos neurônios. Além disso, a glutamina pode ser usada como combustível ou precursor de outras moléculas. Por esse motivo no cérebro, a troca de glutamato, GABA e glutamina é fundamental para a manutenção metabólica e o reservatório de neurotransmissores. O glutamato é liberado pelos neurônios em um processo dependente de $\mathrm{Ca}^{+2}$ que envolve a fusão de vesículas, e seu excesso pode ser tomado pelos astrócitos em um processo 
dependente de $\mathrm{Na}^{+}$e convertido em glutamina ou em $\alpha$-cetoglutarato (Simão et al., 2016; Hertz \& Rothman, 2017; Hayashi, 2018).

Essa atividade metabólica compartimentalizada entre neurônios e astrócitos também é importante, pois inativa os íons $\mathrm{NH}_{4}^{+}$, que são um produto normal do metabolismo desses neurotransmissores (Figura 9.2). No entanto, no SNC, eles são um importante agente neurotóxico, sendo necessário removê-los das sinapses. Nos tecidos, os sais de amônio e a amônia livre $\left(\mathrm{NH}_{3}\right)$ estão em equilíbrio, sendo que em $\mathrm{pH} 7,4$ predomina $(98,3 \%)$ a forma protonada $\left(\mathrm{NH}_{4}^{+}\right.$, ou cátion amônio). No entanto, o termo "amônio" designa ambas as formas, a livre e a protonada. Sob condições fisiológicas, a forma não protonada atravessa por difusão as membranas, incluindo a barreira hematoencefálica (BBB) (Cooper, 1993).

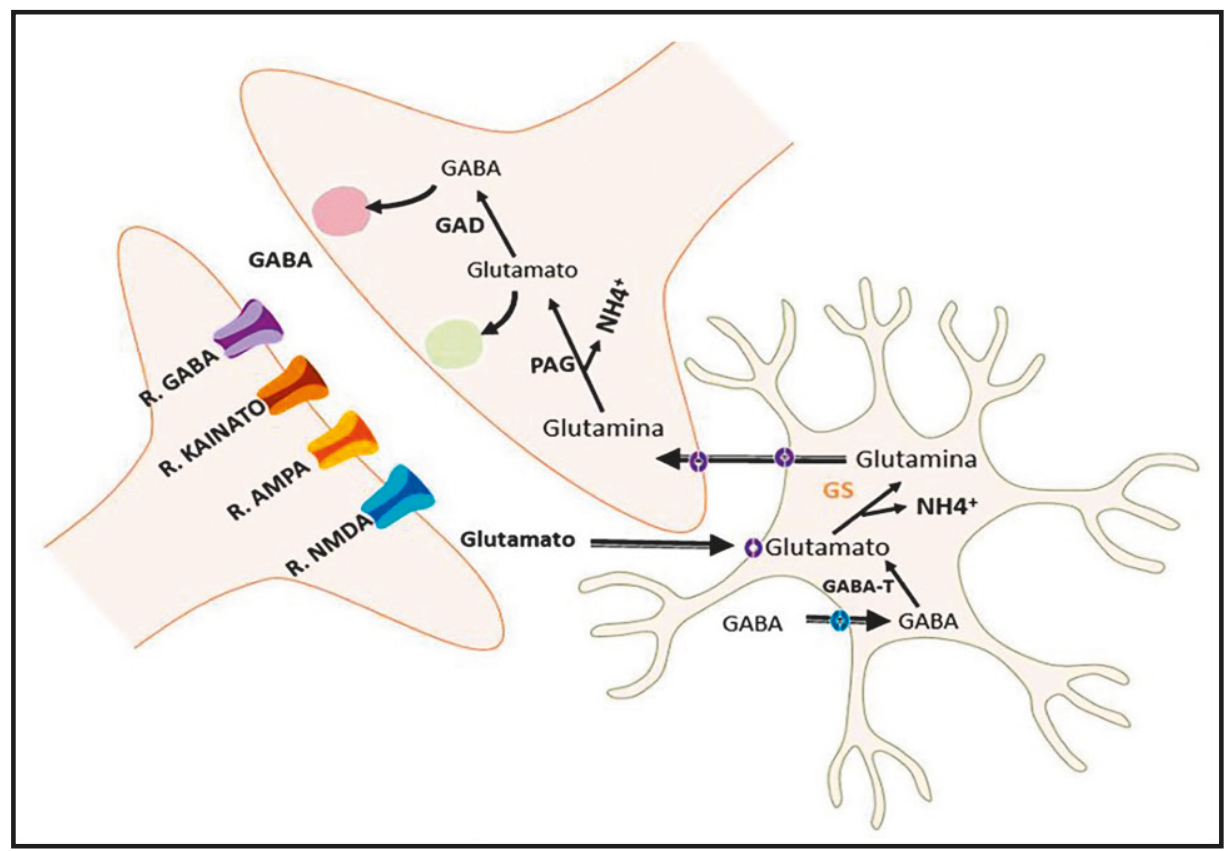

Figura 9.2 - Ciclo glutamato-GABA-glutamina na sinapse tripartite. A compartimentação metabólica dos neurotransmissores é evidenciada para manter a concentração extracelular diminuída e a eliminação dos íons amônio de maneira eficiente.

Fonte: figura adaptada de ppt- toolkit-Neuroscience; https://www.motifolio.com/neuroscience-all.html.

Nesse sentido, o ciclo glutamato-GABA-glutamina também pode ser entendido como um movimento do amônio do terminal sináptico para os astrócitos, operado enzimaticamente e mantido por três mecanismos de transporte de $\mathrm{NH}_{4}^{+}$: a) difusão de $\mathrm{NH}_{4}^{+}$; b) antiporte acoplado a um sistema de lançadeira de 
aminoácidos ramificados e a cetoácidos ramificados; e c) antiporte acoplado à lançadeira alanina-lactato (Maciejewski \& Rothman, 2008).

\subsection{Principais enzimas do ciclo glutamato-GABA-glutamina}

A conversão de glutamato em glutamina ocorre na presença de ATP e $\mathrm{NH}_{4}^{+}$ proveniente do sangue ou do metabolismo no cérebro. Essa reação é catalisada pela enzima glutamina sintetase (GS), conforme a seguir:

$$
\text { Glutamato }+\mathrm{NH}_{4}^{+}+\mathrm{ATP} \rightarrow \text { Glutamina }+\mathrm{ADP}+\mathrm{Pi}
$$

A glutamina sintetase (GS) (E.C. 6.3.1.2) é uma enzima presente em todas as espécies e em quase todos os tecidos e catalisa a conversão de glutamato em glutamina na presença de ATP (Meister, 1985; Daikhin \& Yudkoff, 2000). A GS está envolvida no balanço metabólico e na reciclagem de aminoácidos para o normal funcionamento do cérebro. Classicamente, esta enzima foi relatada exclusivamente em astrócitos (Svenneby \& Torgner, 1987) e a atividade da GS está relacionada com a maturação dessas células (Caldani et al., 1982).

No adulto, a imunorreatividade da GS está associada a processos astrocíticos em torno das sinapses excitatórias (Derouiche \& Frotscher, 1991; Miyake \& Kitamura, 1992). Foi sugerido que os níveis extracelulares de glutamato podem regular a distribuição da GS. Isso mostra a grande importância desses mecanismos de compartimentalização metabólica (Derouiche \& Frotscher, 1991). A meia-vida da enzima é relativamente curta (13-22 h) e os níveis de GS são altamente regulados. A expressão e atividade de GS são moduladas por hormônios como insulina, hormônio tireoidiano e hormônios corticosteroides (Suárez et al., 2002).

A formação de glutamina nos astrócitos a partir do glutamato liberado nas sinapses é a base do ciclo da glutamina (Figura 9.3). A compartimentalização da GS nos astrócitos é consistente com a missão de reciclar glutamato, mantendo o tráfego funcional, e a ausência de GS nos neurônios é consistente com a neurotransmissão excitatória em condições normais (Maciejewski \& Rothman, 2008). No entanto, em condições patológicas como a doença de Alzheimer (DA), por exemplo, essa enzima foi encontrada em neurônios piramidais das camadas 5 e 6 (Walton \& Dodd, 2007). Essa expressão alterada em condições patológicas mostra que a reciclagem de neurotransmissores na sinapse é fundamental para manter a baixa concentração de glutamato e, portanto, poderia funcionar como 
um mecanismo de proteção contra a estimulação excessiva de receptores, o que gera excitotoxicidade nessas condições.

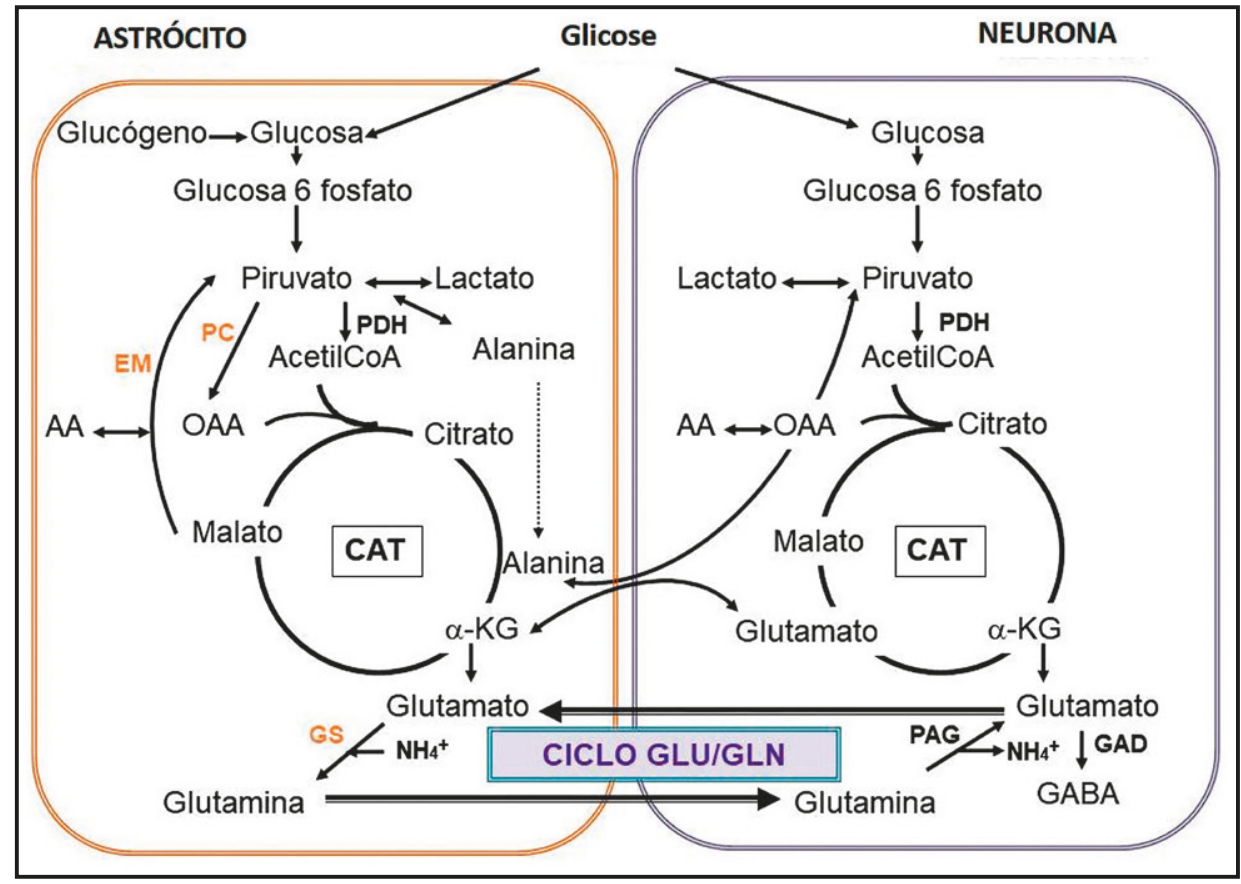

Figura 9.3 - Compartimentação metabólica entre neurônios e astrócitos. Destacam-se as principais vias metabólicas nessas células e o ciclo glutamato-GABA-Glutamina.

Fonte: figura adaptada de ppt- toolkit-Neuroscience; https://www.motifolio.com/neuroscience-all.html.

Considerando outro elemento do compartimento multicelular para o ciclo glutamato-GABA-glutamina, tem-se que nos neurônios se expressam outras enzimas como a glutaminase ativada pelo fosfato (PAG) (E.C. 3.5.1.2), enzima mitocondrial que catalisa a reação não reversível, descrita a seguir:

$$
\text { Glutamina }+\mathrm{H}_{2} \mathrm{O} \rightarrow \text { glutamato }+\mathrm{NH}_{4}^{+}
$$

O fosfato inorgânico é derivado da hidrólise de ATP e o $\mathrm{K}_{\mathrm{M}}$ característico da enzima é muito baixo para seu substrato, o que confere uma alta afinidade pela glutamina. A PAG também inicia o catabolismo da glutamina, o qual é muito importante para os processos biológicos celulares (Kovacevic \& McGivan, 1983). 
A glutamina é transportada ao neurônio mediante dois mecanismos: um $\mathrm{Na}^{+}$dependente e outro $\mathrm{Na}^{+}$independente (Daikhin \& Yudkoff, 2000). A enzima é ativada por fosfato e por ácidos carboxílicos e inibida por glutamato, amônio e prótons. A PAG está presente tanto em astrócitos como em neurônios, porém é principalmente ativa em neurônios, o que favorece a síntese em terminais pré-sinápticos e é consistente com a compartimentalização em condições normais (Maciejewski \& Rothman, 2008). Assim, a PAG produz glutamato e $\mathrm{NH}_{4}^{+} \mathrm{em}$ neurônios e a GS utiliza glutamato e $\mathrm{NH}_{4}^{+}$em astrócitos.

O transporte de glutamato dos terminais sinápticos e o transporte de glutamina do astrócito são processos dependentes de ATP. Somado a isso, as reações catalisadas por GS e PAG também são ATP dependentes; por conta disso, o balanço energético celular acaba sendo crítico no acoplamento do ciclo glutamato-glutamina com os substratos necessários para sua manutenção, os quais, no cérebro, são dependentes de glicose (Maciejewski \& Rothman, 2008).

A circulação de glutamato nas sinapses para a neurotransmissão é fundamental para o funcionamento do cérebro, devido à grande maioria de sinapses serem glutamatérgicas e mediarem funções vitais como a aprendizagem, a formação de memória, reconhecimento espacial e funções superiores da consciência. Adicionalmente, tanto neurônios como astrócitos podem utilizar, oxidativamente, o glutamato pela ação da glutamato desidrogenase $\mathrm{NAD}(\mathrm{P})^{+}$(E.C. 1.4.1.2-4), rota potencialmente importante para a entrada de esqueletos de carbono no ciclo dos ácidos tricarboxílicos (CAT). Em astrócitos ácidos como citrato e malato, gerados no CAT ou pela atividade da enzima málica (EC 1.1.1.40), poderiam ser exportados para serem utilizados, principalmente, pelos neurônios como esqueletos de carbono precursores de glutamato e permitir, assim, a manutenção do ciclo glutamato/glutamina (Maciejewski \& Rothman, 2008). Devido a que no cérebro não procede a aminação redutiva do $\alpha$-cetoglutarato para produzir glutamato, exceto sob condições de hiperamonemia (Cooper et al., 1979), a formação de glutamato pode ocorrer por transaminação com aminoácidos como a alanina, reação catalisada pela alanina aminotransferase (EC 2.6.1.2).

A alanina também pode ser produzida nos astrócitos a partir de piruvato, por transaminação, ou por oxidação parcial de glicose na glicólise, como foi demonstrado no cultivo de neurônios (Peng, Schousboe \& Hertz, 1991) e no cérebro in vivo (Bakkelund et al., 1993).

Glutamato + Piruvato $\longleftrightarrow$ Alanina $+\alpha$-cetoglutarato 
A formação de alanina a partir de piruvato por transaminação com glutamato, está em equilíbrio pela transaminação entre alanina e $\alpha$-cetoglutarato para produzir piruvato, que é oxidado no CAT, e glutamato (Peng et al., 1994). O doador de grupos amino para as transaminações com $\alpha$-cetoglutarato pode ser também um aminoácido ramificado como valina, leucina ou isoleucina; todos eles aminoácidos essenciais que atravessam facilmente a BBB (Smith et al., 1987).

O destino do glutamato não é só o de aumentar o reservatório de neurotransmissores na célula pré-sináptica; a conversão de glutamato a $\alpha$-cetoglutarato é uma transaminação na qual intervém também aspartato aminotransferase (EC 2.6.1.1), reação que favorece o equilíbrio para a formação de aspartato (Erecinska et al., 1990).

\section{Glutamato + Oxalacetato $\longleftrightarrow$ Aspartato $+\alpha$-cetoglutarato}

Por desaminação redutiva, catalisada pela glutamato desidrogenase NAD(P) , é favorecida a utilização de esqueletos de carbonos provenientes do glutamato com produção de $\alpha$-cetoglutarato como combustível via CAT (McKenna et al., 1996).

$$
\alpha \text {-cetoglutarato }+\mathrm{NH}_{4}^{+}+\mathrm{NAD}(\mathrm{P}) \mathrm{H} \leftrightarrows \text { Glutamato }+\mathrm{NAD}(\mathrm{P})^{+}+\mathrm{H}_{2} \mathrm{O}
$$

Também é importante a ação da enzima piruvato carboxilase (EC 6.4.1.1) (enzima glial) a qual favorece a carboxilação do piruvato nos astrócitos com produção de oxalacetato. Isso aumenta a concentração de intermediários do CAT e, portanto, a concentração de $\alpha$-cetoglutarato que, por transaminação com alanina, leva à produção de glutamato (Figura 9.3). Dessa forma, os intermediários do ciclo são precursores para a síntese de neurotransmissores, neste caso o glutamato, assim como para a oxidação e produção de ATP (Hertz et al., 1999).

Todas essas reações favorecem a incorporação dos esqueletos de carbono, provenientes do glutamato, ao CAT na forma de $\alpha$-cetoglutarato o qual, por ação do complexo multienzimático $\alpha$-cetoglutarato desidrogenase, produz succinil coenzima A (succinil-CoA) (Hertz et al., 1999). Foi verificado que o glutamato convertido em $\alpha$-cetoglutarato pode ser completamente oxidado a $\mathrm{CO}_{2}$ e água nos astrócitos (Schousboe et al., 1993) e no cérebro intacto de ratos (Pascual et al., 1998). O $\alpha$-cetoglutarato pode abandonar a matriz mitocondrial, por meio de sua conversão em malato no CAT, através de um transportador de dicarboxilato que se expressa na membrana interna mitocondrial e, uma vez no citossol, é 
convertido em piruvato numa reação catalisada pela enzima málica que se encontra expressa somente na glia. O piruvato pode ser reintroduzido ao CAT para sua completa oxidação até $\mathrm{CO}_{2}$ e água (McKenna et al., 1996; Simão et al., 2016; Magistretti \& Allaman, 2018).

\subsection{Regulação do ciclo glutamato-GABA-glutamina}

Este ciclo requer um metabolismo altamente regulado, a fim de que tanto a síntese da glutamina como sua degradação não se convertam em um ciclo inútil. Devido ao fato de a síntese de glutamina catalisada por GS ser dependente de ATP, a regulação do consumo energético acaba sendo também vital para a célula, assim como a inter-relação dos processos. Entretanto, é pouco o que se conhece dos mecanismos regulatórios em mamíferos e, particularmente, no SNC; porém, existe ampla informação em sistemas bacterianos.

Procariontes e eucariontes expressam formas diferentes de GS. Os procariontes expressam GS tipo I (GSI), enquanto que eucariontes expressam GS tipo II (GSII). A GS bacteriana consiste num complexo enzimático de 12 subunidades, enquanto que para as GS eucarióticas foram reportados complexos de 8 a 10 subunidades organizadas em dois tetrâmeros ou pentâmeros, respectivamente. Pesquisas sobre GS têm sido realizadas nos seguintes tecidos: fígado de rato e músculo esquelético de rato e coelho (Meister, 1985), cérebro de porco (Jaenicke \& Berson, 1977), cérebro de ovelha (Maurizi et al., 1987) e cérebro humano (Tumani et al., 1999; Boksha et al., 2002).

Em relação à regulação da atividade enzimática, existem relatos da inibição de GSII por APD no músculo esquelético de rato, enquanto que no cérebro e fígado não há esse tipo de regulação (Meister, 1985). Os sítios de interação alostérica de GSII foram propostos para arsenato, glutamato e dois íons $\mathrm{Mn}^{+2}$ por subunidade. Outros íons que afetam a atividade de GSII são o íon $\mathrm{Cl}^{-}$e, para a GS do cérebro de ovelha foram reportados quatro $\mathrm{Mn}^{+2}$, unidos fortemente por octâmero (Sidoryk-Wegrzynowicz \& Aschner, 2013), em contraste com GS de cérebro de bovino, no qual foram reportados $16 \mathrm{Mn}^{+2}$ por octâmero, porém não fortemente unidos (Maurizi et al., 1987). Nesse sentido, foi demonstrado que a exposição ao $\mathrm{Mn}^{+2}$ causa transporte aberrante de glutamato nos astrócitos, levando a altas concentrações de glutamato extracelular. Além disso, o $\mathrm{Mn}^{+2}$ provoca uma regulação negativa da expressão e atividade da GS. Essas alterações podem desencadear o esgotamento da síntese de glutamina na glia com a diminuição e, portanto, o desequilíbrio do ciclo afetando as sinapses glutamatérgicas e GABAérgicas (Sidoryk-Wegrzynowicz \& Aschner, 2013). 
Por outro lado, todas as GSII perderam a sequência de adenilação e não exibem esse mecanismo regulatório, como é o caso das GSI, e não se inibem pelo acúmulo de produtos finais (Eisenberg et al., 2000). Quanto à regulação da expressão gênica da GS, foi reportado que está determinada por hormônios como insulina e hidrocortisona, que podem induzir mudanças nas taxas de biossíntese da enzima (Meister, 1985).

\section{GLUTAMINA E METABOLISMO OXIDATIVO NO CÉREBRO}

O metabolismo energético do cérebro depende exclusivamente do uso da glicose e da oxidação completa dessa molécula nas mitocôndrias, tornando o cérebro especialmente suscetível a danos oxidativos devido à alta produção de espécies reativas de oxigênio (ERO), à presença de ácidos graxos poli-insaturados nas membranas celulares, assim como ao fato do cérebro ter, relativamente, baixa defesa antioxidante. As ERO participam no dano provocado, entre outros, pelos processos neurodegenerativos, incluindo morte celular, desordens motoras e lesões. Por outro lado, as disfunções por deficiências na defesa antioxidante têm sido associadas a quase todas as doenças neurodegenerativas (Matés et al., 1999).

A glutamina tem um papel importante no controle antioxidante e na resposta celular redox. Na doença de Alzheimer (DA), o peptídeo beta amiloide (PBA) e a apolipoproteína E (APOE) contribuem em potencializar os eventos de estresse oxidativo que disparam apoptose (Fadeel et al., 1999). A glutamina, como precursora de glutationa, ajuda a elevar os níveis que protegem contra os efeitos deletérios das ERO (Amores-Sánchez \& Médina, 1999).

O radical óxido nítrico (NO), por exemplo, é uma ERO produzida em organismos superiores pela oxidação de um dos nitrogênios do guanidino terminal da L-arginina, pela óxido nítrico sintase. Dependendo do microambiente, o NO pode ser convertido em outras espécies reativas de nitrogênio (ERN), como são o cátion nitroso $\left(\mathrm{NO}^{+}\right)$, dióxido de nitrogênio $\left(\mathrm{NO}_{2}\right)$ ou o peroxinitrito $\left(\mathrm{ONOO}^{-}\right)$ (Droge, 2002; Belzer \& Hanani, 2019).

Vários trabalhos demonstraram que o NO funciona como um neurotransmissor envolvido na regulação neuroendócrina (Belzer \& Hanani, 2019). Assim, neurônios que sintetizam NO estão presentes nos núcleos hipotalâmicos estreitamente associados com neurônios produtores de hormônios hipotalâmicos liberadores de hormônios hipofisiários, como o hormônio liberador de gonadotropinas (GnRH), o hormônio liberador do hormônio do crescimento (GH-RH) e de hormônios adenoipofisários como a prolactina (PRL) (Aguan et al., 1996). 
O óxido nítrico é sintetizado por uma família de enzimas conhecidas como óxido nítrico sintase (NOS), das quais se conhecem três isoformas. Uma delas neuronal (nNOS ou NOS1), de onde originalmente foi clonada, ainda que também esteja presente no rim e músculo esquelético (Droge, 2002). NOS1 tem um papel fisiológico importante, em nível neuronal, na liberação de neurotransmissores, no desenvolvimento neuronal, na regeneração, na plasticidade sináptica e na regulação da expressão de genes. No entanto, a desregulação desta enzima tem sido relacionada a uma ampla variedade de distúrbios como a doença de Alzheimer (DA) e a doença de Parkinson (DP), em que a produção excessiva de NO é evidenciada em lesões cerebrais, onde se comporta como mediador de neurotoxicidade (Droge, 2002).

Adicionalmente, no cérebro, a GS é modulada por NMDA e NO. Assim, o bloqueio dos receptores ou da atividade de NOS in vivo aumenta a atividade de GS e o conteúdo de glutamina no cérebro, indicando que uma ativação dos receptores NMDA e NOS mantém uma inibição da GS. Isso é devido a que a ativação de NOS é mediada pelos receptores NMDA, sendo responsáveis apenas em parte pela inibição da enzima. Outras fontes de NO podem contribuir para a inibição da GS por efeito de modificações covalentes reversíveis na enzima, como a nitração de resíduos de tirosina, o que torna a enzima menos eficiente (Rodrigo \& Felipo, 2007).

\section{PATOLOGIAS ASSOCIADAS AO DESBALANC̦O DO CICLO GLUTAMATO-GABA-GLUTAMINA}

O conhecimento de que as atividades cerebrais envolvem uma grande interação entre os neurônios e a glia, inicia todo um universo de entendimento de diferentes patologias. Alterações na glia disparam ou potencializam um grande impacto nas atividades nas redes neurais e, em muitos casos, poderiam favorecer as primeiras manifestações celulares e bioquímicas que, posteriormente, levem a processos de neurodegeneração. Sabe-se que processos inflamatórios e de ativação glial "astrocitose" produzem profundas alterações estruturais entre as interações neurônio-astrócito (Pekny \& Nilsson, 2005; Maragakis \& Rothstein, 2006).

Somado a isso, as funções normais do cérebro requerem um balanço entre a energia requerida para as atividades e o fornecimento de nutrientes o qual, no $\mathrm{SNC}$, é principalmente dependente de glicose. Dados recentes indicam que esses dois processos estão altamente acoplados e que a reciclagem de glutamato pelos astrócitos resulta em um processo crucial neste acoplamento. Assim, a utilização 
de glicose pelos astrócitos é principalmente através da glicólise, o que conduz à produção de lactato o qual, posteriormente, é exportado aos neurônios onde é utilizado para o metabolismo oxidativo ou para a síntese de neurotransmissores (Poitry et al., 2000). Em contraste, o glutamato liberado dos neurônios é captado pelos astrócitos e incluído no ciclo glutamato-GABA-glutamina.

Com essas observações, é proposto um modelo no qual se expõe que o consumo de glicose do astrócito está acoplado à captura de glutamato nos astrócitos. O modelo implica que o consumo de energia glia-neurônio está potencializado em função da atividade sináptica (Pellerin \& Magistrettri, 1994; Pellerin \& Magistretti, 2012). Estudos de ressonância magnética nuclear ${ }^{13} \mathrm{C} \mathrm{NMR}$ em córtex de ratos e humanos confirmam uma relação estequiométrica 1:1 de consumo de glicose e a reciclagem de glutamato (Shen et al., 1999).

$\mathrm{O}$ exposto anteriormente implica que, em condições de insuficiência energética, se espera encontrar alterações no nível do ciclo glutamato-GABA-glutamina. Nesse sentido, a modulação da atividade de GS e de outras enzimas no cérebro resulta ser importante e qualquer alteração ou saturação resulta em consequências potencialmente patológicas. As patologias a seguir mostram algumas evidências que apoiam essa afirmação.

\subsection{Doença de Alzheimer}

A doença de Alzheimer (DA) é a causa de demência mais frequente na população idosa, representando entre 50 e $80 \%$ do total das demências. Sua forma de apresentação se caracteriza pela aparição de transtornos mentais, tais como ideias de perseguição, alteração da memória, desorientação tempo-espacial, problemas de compreensão de linguagem, diminuição da memória e conversação desconexa (Villemagne et al., 2013). Em geral, aparece depois dos 50 anos de idade e nem sempre acompanha sintomas tais como alteração no andar, coordenação de movimentos ou alterações nos reflexos. Em nível molecular, se reconhece que, nos estados avançados de DA, são encontrados acúmulos do peptídeo $\beta$-amiloide (PBA), o qual é derivado por clivagens sequenciais de uma glicoproteína precursora transmembrânica. O PBA é um peptídeo de 42 aminoácidos e constitui o núcleo das placas neuríticas (placas de Alzheimer ou placas senis) (Querfurth \& Laferla, 2010). As alterações em seu processamento metabólico e o seu posterior acúmulo são algumas das características nos estados avançados da DA.

Durante anos, prevaleceu a hipótese de que o glutamato é o principal responsável pelo processo de patogênese, devido a terem sido encontradas elevadas 
concentrações desse neurotransmissor no meio extracelular em pacientes diagnosticados com DA (Le Prince et al., 1995). Um estudo com pacientes que apresentavam comprometimento cognitivo ou possível DA verificou que os níveis de glutamato e glutamina aumentam no líquido cefalorraquidiano (LCR) (ou fluido cérebro espinhal), de modo que podem ser considerados biomarcadores adicionais no comprometimento cognitivo pré-clínico, ou nos estágios iniciais da demência (Madeira et al., 2018). Outro estudo comparou os níveis de glutamato, glutamina e GABA em jovens e idosos saudáveis, verificando que eles podem diminuir simultaneamente com a idade, embora esses níveis diminuam predominantemente na doença em pacientes que apresentam comprometimento cognitivo e pacientes com diagnóstico de DA. Esses estudos sugerem que o equilíbrio de excitação/inibição pode ser afetado na DA, o que poderia contribuir para a patogênese (Huang et al., 2017).

Devido a que o aumento extracelular de glutamato provoca efeito tóxico sobre os neurônios, dado principalmente por superestimulação dos receptores de glutamato, particularmente os NMDA, desencadeiam-se uma série de eventos que são disparados por um aumento intracelular de $\mathrm{Ca}^{+2}$ e que geram morte celular. Esse mecanismo é conhecido como "excitotoxicidade por glutamato" (Boksha, 2004). Apesar de todo esse conhecimento, ainda não é claro quais componentes do sistema glutamatérgico se encontram alterados. Adicionalmente, o excesso de glutamato não só tem efeitos sobre os neurônios, visto que os astrócitos, abundantes nos terminais glutamatérgicos, também se veem afetados, já que o aumento da concentração do glutamato provoca turgor e, finalmente, lise celular (Chen et al., 2000).

$\mathrm{O}$ rápido aumento extracelular de glutamato provoca excitotoxicidade em poucos minutos. Assim, a súbita perda de suprimento de energia devido ao desligamento do fluxo sanguíneo ao cérebro leva a um colapso dos potenciais de membrana neuronal e astroglial, uma vez que a manutenção destes depende de energia. Nos neurônios, a despolarização subsequente da membrana leva à liberação vesicular de glutamato. Além da depleção de energia e a interrupção da homeostase iônica, a atividade dos EAAT também é inibida nos astrócitos e, inclusive, pode-se até induzir uma reversão em sua ação, levando à liberação de glutamato não vesicular (Lewerenz \& Maher, 2015).

Sob esse contexto, espera-se que as patologias no SNC resultem das mudanças no sistema glutamatérgico, principalmente, em dois níveis diferentes: a) na distribuição e expressão de diferentes transportadores, receptores e enzimas, o que leva a diferenças na regulação; e b) impacto nas rotas implicadas no 
metabolismo do glutamato para a síntese ou inativação. Tem havido relatos sobre diversas enzimas, como PAG e GS, estarem alteradas na DA. Em particular, foi encontrada drasticamente diminuída a expressão de PAG em neurônios corticais de pacientes com DA, além da queda no número de neurônios que expressam outras enzimas, como glutamato desidrogenase (Akiyama et al., 1989). Nesse mesmo sentido, foi detectada uma baixa atividade dos transportadores para glutamato tipo GLT1 (Procter et al., 1988). Outros estudos histológicos post-mortem de pacientes com DA revelaram um decréscimo na expressão e na atividade da GS (Le Prince et al., 1995). Essas observações são consistentes com que alterações em diferentes componentes do sistema glutamatérgico levem a mudanças deletérias no contexto funcional e, como consequência, conduziriam ao cenário perfeito para disparar eventos moleculares que levam à neurodegeneração típica dessas patologias.

Adicionalmente, tem sido relatado que a perda da atividade da GS pode estar relacionada com a formação de radicais livres ou por suscetibilidade da enzima à presença dos mesmos, sugerindo um dano estrutural que seria responsável pela perda de atividade da GS. A sensibilidade da GS à inativação por agentes oxidantes, que geralmente modificam sua atividade, tem sido usada como uma medida do dano no tecido cerebral (Aksenov et al., 1997). Resultados usando um modelo de camundongo triplo-transgênico (3xTg-AD) indicam que a diminuição na expressão da GS pode estar subjacente a uma diminuição gradual na via vital de conversão de glutamato a glutamina dependente de astrócitos, que por sua vez pode comprometer a homeostase do glutamato, levando a falhas na conectividade sináptica, cognição e falta de memória (Kulijewicz-Nawrot et al., 2013).

A manutenção do nível de glutamato depende da compatibilização dos processos de captura e transporte, em contraposição com os mecanismos metabólicos de produção e interconversão. Nesse sentido, as observações evidenciam um decréscimo da expressão da GS em astrócitos e uma expressão alterada em neurônios piramidais em todos os casos de pacientes estudados (Robinson, 2001; Walton \& Dodd, 2007; Fernandes et al., 2011), o que indica alteração no ciclo glutamato/glutamina em pacientes com DA. A expressão alterada da enzima poderia obedecer a um mecanismo de compensação do sistema para contrastar o efeito adverso, a fim de "inativar" intracelularmente o glutamato em um compartimento diferente e operar parcialmente o sistema.

Adicionalmente, usando-se modelos in vitro, foi demonstrada a interação de GS com o fragmento PBA 1-40 e o fragmento PBA 25-35, resultando na 
ativação oxidativa da GS e num incremento da formação de radicais com o aumento da neurotoxicidade, em consequência do peptídeo (Butterfield et al., 1997; Canevari et al., 2004). Essas observações sugerem que existe uma relação entre a interação da enzima com PBA e a formação da placa amiloide, que poderia ser evidenciada com o compromisso na toxicidade por glutamato e amônio. Foi reportado também que os PBA facilitam a formação de radicais livres reativos (Butterfield et al., 1997; Butterfield et al., 2007) e foi proposto que esses radicais livres derivados de PBA podem causar dano às proteínas celulares, ao provocar modificações por oxidação. Uma explicação para esse efeito neurotóxico dos PBA é a potencialização do estresse oxidativo, além de alterações na atividade de enzimas do metabolismo intermediário e disfunção mitocondrial (Atamna \& Frey, 2007). Existem relatos de outros estudos in vitro, nos quais foi colocado em evidência que os PBA 1-40 sintéticos interagem com a GS e a inativam, induzindo oxidação na enzima pura (Butterfield et al., 2007).

Outros trabalhos mostram que, em condições normais como o envelhecimento, há uma diminuição da atividade de GS com incremento nas concentrações de amônio e glutamato extracelular (Huang et al., 2017). Pacientes com DA mostram níveis ainda mais baixos de atividade da enzima, especialmente nas vizinhanças das placas senis e nos depósitos amiloides característicos da doença, nos quais predomina a presença de PBA. Adicionalmente, foi observada a expressão neural da enzima (Robinson, 2001). Todas essas alterações intracelulares precoces poderiam ser um indicativo de dano tissular. Além disso, a GS foi relatada estar presente no fluido cérebro espinal (FCE), o que sugere mudanças na compartimentalização, na expressão da GS e metabolismo alterado ou disfuncional do glutamato (Tumani et al., 1999).

\subsection{Doença de Huntington}

A doença de Huntington (DH) (ou coreia de Huntington) é um transtorno progressivo que ocasiona degeneração das células nervosas no cérebro e foi descrita inicialmente em 1872 por George Huntington, um médico norte-americano. Nela, se apresenta perda progressiva da função mental, mudanças de personalidade e perda das funções cognitivas como o juízo e linguagem. Também se desenvolvem movimentos faciais e corporais espasmódicos rápidos e anormais. O termo coreia indica "dança" e se refere aos movimentos atípicos que se desenvolvem durante a enfermidade. Nas formas juvenis da enfermidade, os pacientes apresentam distonia e sinais que evidenciam efeitos adversos da função cognitiva e psiquiátrica (Chesselet, 2001). Uma característica dessa patologia é a presença 
de agregados de uma proteína de $350 \mathrm{kDa}$ denominada huntingtina que apresenta uma expansão de poliglutaminas na região N-terminal (mais de 37 glutaminas). Esse fragmento determina o acúmulo da proteína no núcleo, afetando a regulação da transcrição e o desencadeamento da neuropatologia (Havel et al., 2009).

$\mathrm{Na} \mathrm{DH}$, ainda que os mecanismos patogênicos até agora não tenham sido bem entendidos, o denominador comum parece ser uma alteração no ciclo glutamato-GABA-glutamina. Em estudos da doença com ratos transgênicos e com camundongos R6/2, foi identificado que o mecanismo de excitotoxicidade se encontra associado a essa entidade neurodegenerativa e, nesse caso, compromete a atividade dos transportadores de glutamato. Relatos da literatura apoiam a opinião de que na DH existe uma redistribuição dos receptores de NMDA, especialmente a subunidade NR2B, que poderiam superativar vias de sinalização que promovam a neurodegeneração. Contudo, não há evidências consistentes de que os níveis extracelulares de glutamato cerebral aumentem consideravelmente na doença (Lewerenz \& Maher, 2015). Da mesma forma, foi observado um aumento nos níveis extracelulares de glutamina, resultante da diminuição da atividade da GS nas células gliais ou de decréscimo da capacidade de captura do neurotransmissor pelas células neuronais. Ainda que a utilização de glutamina possa estar alterada devido a uma deficiência na atividade da PAG, nesse estudo não foi encontrada mudança na expressão (Behrens et al., 2002). Porém, sabe-se que em pacientes com DH foi verificada reduzida atividade da PGA (Butterworth et al., 1985).

A atividade da GS foi medida em áreas de cérebro post-mortem em pacientes com DH, encontrando-se reduzida no córtex frontal, córtex temporal, putâmen e cerebelo. Esses resultados sugerem que, nas áreas onde se apresenta redução, existe um deficit funcional (Carter, 1982).

Em um estudo usando modelos de camundongos específicos para neurônios, astrócitos ou ambas as populações do circuito dos gânglios da base, foi expresso um fragmento de huntingtina. Assim, foi demonstrado que os astrócitos são menos afetados pela huntingtina em comparação aos neurônios, particularmente no que diz respeito à agregação. Além disso, foi observada uma contribuição mais indireta dos astrócitos em comparação com os neurônios em vários mecanismos fisiopatológicos, como a astrogliose e a disfunção neuronal (Meunier et al., 2016).

\subsection{Doença de Parkinson}

A doença de Parkinson (DP) (ou mal de Parkinson) foi descrita, inicialmente, pelo médico James Parkinson, em 1817, a quem se deve o nome dessa 
enfermidade. No início, o Dr. Parkinson a chamou Paralisis Agitans, o que define os sintomas da doença, ou seja, a associação de lentidão com movimentos anormais. A DP é uma desordem do sistema nervoso central, na qual se apresentam perda do controle motor, tremor, bradiquinésia, rigidez muscular e instabilidade postural (Hayes, 2019). A DP pode se iniciar desde a segunda década da vida até o final da mesma, com um pico máximo de prevalência entre a quinta e a sexta década da vida. Pode-se dizer que é um mito que a DP seja exclusiva da velhice, dado que pode haver DP juvenil e infantil. A característica mais importante, do ponto de vista da patogenia, é a perda seletiva de neurônios dopaminérgicos na substância nigra (nigra pars compacta), pela formação de inclusões anormais de proteína conhecidas como corpos de Lewy, compostos principalmente de $\alpha$-sinucleína e da proteína parkinina (Hayes, 2019).

A DP está associada com morte de neurônios, especialmente dopaminérgicos, ainda que os mecanismos que causem essa degeneração ainda não sejam totalmente compreendidos. Existe evidência indireta que sugere que os mecanismos da atividade excitatória do glutamato poderiam regular a patogênese da DP (Meredith et al., 2009, Zhang et al., 2016). A superestimulação dos neurônios glutamatérgicos e o efeito benéfico observado com substâncias antiglutamatérgicas, em modelos animais, sugerem que o excesso de glutamato pode contribuir na patofisiologia da DP. Adicionalmente, foi encontrada reduzida a atividade da GS em pacientes com DP, em relação a pacientes-controles de mesmas idades. Esses resultados implicam numa desregulação no ciclo glutamato/glutamina, manifestada na alteração da enzima em pacientes com DP (Meredith et al., 2009).

Conforme mencionado anteriormente, a neurotransmissão excitatória consome importantes quantidades de ATP, principalmente para os sistemas de transporte. Estudos que utilizam cultivos de neurônios dopaminérgicos de humanos e ratos, que são submetidos a concentrações altas de glutamato, indicam que a ativação da glutamato desidrogenase (GDH) é favorecida com a produção de $\alpha$-cetoglutarato. Assim, ele pode ser usado para manter as demandas de energia próprias dos mecanismos de transporte de glutamato, da atividade da GS e da PAG, todos eles ATP dependentes. Na patogênese da DP, a atividade da GDH neuronal poderia constituir uma fonte adicional de energia metabólica (Plaitakis \& Shashidharan, 2000).

No entanto, outros estudos têm evidenciado que a diminuição da expressão dos EAAT na substância nigra, ou a administração de inibidores, causam os efeitos neurodegenerativos da doença. Esta é uma evidência sólida que confirma 
que a diminuição da expressão de EAAT contribui com o processo de patogênese na DP. Da mesma forma, tem sido demonstrado que os fármacos ou tratamentos que promovem a expressão e a função das EAAT atenuam a morte de neurônios dopaminérgicos na substância nigra e o estriado, melhorando as características do distúrbio em termos de características comportamentais e habilidades cognitivas em modelos animais com DP (Assous et al., 2014; Zhang et al., 2016).

\section{CONSIDERAÇÕES FINAIS}

O glutamato no sistema nervoso central é o aminoácido excitatório mais importante e participa nas principais funções superiores e da consciência. Metabolicamente, provém da glicose e da glutamina que atravessam a barreira hematoencefálica (BBB). Porém, devido a sua importância na fisiologia do cérebro, pode ser considerado que se encontra em quatro grandes compartimentos: a) nas sinapses glutamatérgicas; b) nas sinapses GABAérgicas; c) no compartimento glial; e d) em um reservatório multicelular no qual participam diferentes tipos de enzimas. Isso significa que o glutamato participa, direta ou indiretamente, em todas as atividades cerebrais. Além disso, se houver alterações em nível estrutural ou funcional, em qualquer ponto desses quatro compartimentos, podem ser gerados distúrbios que levam a processos que potencializam o cenário para que, em nível molecular, ocorram manifestações patológicas.

Particularmente, nas doenças neurodegenerativas existem evidências que confirmam que alterações no ciclo glutamato-GABA-glutamina geradas por mudanças relacionadas à expressão gênica devido ao envelhecimento, podem potencializar os mecanismos de excitoxidade característicos dessas entidades patológicas. É por isso que, nos últimos anos, a comunidade de neurocientistas tem se dedicado a entender como o glutamato participa nas atividades metabólicas, de sinalização e transporte, sob diferentes condições. O desafio é entender em que situações podem ocorrer mudanças que alterem o metabolismo normal do glutamato no cérebro, a fim de procurar alternativas terapêuticas para responder a essas alterações, antes que os efeitos se tornem irreversíveis.

\section{REFERÊNCIAS BIBLIOGRÁFICAS}

AGUAN, K. et al. "Evidence for a physiological role for nitric oxide in the regulation of the LH surge: effect of central administration of antisense oligonucleotides to nitric oxide synthase". Neuroendocrinol. 64(6): 449-455, 1996. 
AKIYAMA, H. et al. "Loss of glutaminase-positive cortical neurons in Alzheimer's disease". Neurochem Res. 14(4): 353-358, 1989.

AKSENOV, M. et al. "Oxidative modification of glutamine synthetase by amyloide beta peptide”. Free Rad Res. 27(3): 267-281, 1997.

ALBRECHT, J. et al. "Glutamine in the central nervous system: function and dysfunction". Front Biosci. 12: 332-343, 2007.

AMORES-SÁNCHEZ, M. I. \& MEDINA, M. A. "Glutamine, as a precursor of glutathione, and oxidative stress”. Mol Genet Metab. 67(2): 100-105, 1999.

ARAQUE, A. et al. "Gliotransmitters travel in time and space". Neuron. 81(4): 728-39, 2014.

ARRUBLA, J. et al. "Microstructural and functional correlates of glutamate concentration in the posterior cingulate cortex". J Neurosci Res. 95(9): 1796$1808,2017$.

ASSOUS, M. et al. "Progressive Parkinsonism by acute dysfunction of excitatory amino acid transporters in the rat substantia nigra". Neurobiol Dis. 65: 69-81, 2014.

ATAMNA, H. \& FREY, W. "Mechanisms of mitochondrial dysfunction and energy deficiency in Alzheimer's disease”. Mitochondrion. 7(5): 297-310, 2007.

BAKKELUND, A. H.; FONNUM, F. \& PAULSEN, R. E. "Evidence using in vivo microdialysis that aminotransferase activities are important in the regulation of the pools of transmitter amino acids". Neurochem Res. 18: 411-415, 1993.

BAZARGANI, N. \& ATTWELL, D. "Astrocyte calcium signaling: the third wave". Nat Neurosci. 19(2): 182-189, 2016.

BEHRENS, P. F. et al. "Impaired glutamate transport and glutamate-glutamine cycling: downstream effects of the Huntington mutation". Brain. 125(8): 19081922, 2002.

BELZER, V. \& HANANI, M. "Nitric oxide as a messenger between neurons and satellite glial cells in dorsal root ganglia”. Glia. 67(7): 1296-1307, 2019.

BEZZI, P. \& VOLTERRA, A. "A neuron-glia signalling network in the active brain”. Curr Opin Neurobiol. 11(3): 387-394, 2001. 
BILLARD, J. M. "Changes in serine racemase-dependent modulation of NMDA receptor: impact on physiological and pathological brain aging". Front Mol Biosci. 5:106, 2018.

BLIIM, N. et al. "Early transcriptome changes in response to chemical long-term potentiation induced via activation of synaptic NMDA receptors in mouse hippocampal neurons". Genomics. 111(6):1676-1686, 2019.

BOKSHA I. S. "Coupling between neuronal and glial cells via glutamate metabolism in brain of healthy persons and patients with mental disorders". Biochemistry (Mosc). 69(7): 705-719, 2004.

BOKSHA, I. S. et al. "Glutamine synthetase isolated from human brain: octameric structure and homology of partial primary structure with human liver glutamine synthetase". Biochemistry (Mosc). 67(9): 1012-1020, 2002.

BUTTERFIELD, D. A. et al. "Oxidatively induced structural alteration of glutamine synthetase assessed by analysis of spin label incorporation kinetics: relevance to Alzheimer's disease". J Neurochem. 68(6): 2451-2457, 1997.

BUTTERFIELD, D. A. et al. "Roles of amyloid beta-peptide-associated oxidative stress and brain protein modifications in the pathogenesis of Alzheimer's disease and mild cognitive impairment". Free Radic Biol Med. 43(5): 658-677, 2007.

BUTTERWORTH, J.; YATES, C. M. \& REYNOLDS, G. P. "Distribution of phosphateactivated glutaminase, succinic dehydrogenase, pyruvate dehydrogenase and gamma-glutamyl transpeptidase in post-mortem brain from Huntington's disease and agonal cases". J Neurol Sci. 67(2):161-171, 1985.

CALDANI, M. et al. "Glutamine synthetase activity during mouse brain development. Experientia”. 38(10):1199-202, 1982.

CALÌ, C.; TUFFENBERGER, A. \& MAGISTRETTI, P. “The strategic location of glycogen and lactate: from body energy reserve to brain plasticity". Front Cell Neurosci. 13: 82, 2019.

CANEVARI, L.; ABRAMOV, A. \& DUCHEN, M. "Toxicity of amyloid beta peptide: tales of calcium, mitochondria, and oxidative stress". Neurochem Res. 29(3): 637-650, 2004.

CARTER, C. J. "Glutamine synthetase activity in Huntington's disease". Life Sci.31(11): 1151-1159, 1982. 
CHEN, S. \& GOUAUX, E. "Structure and mechanism of AMPA receptor - auxiliary protein complexes". Curr Opin Struct Biol. 54: 104-111.

CHEN, C. J.; LIAO, S. L. \& KUO, J. S. "Gliotoxic action of glutamate on cultured astrocytes”. J Neurochem. 75(4): 1557-1565, 2000.

CHESSELET, M. (ed.). Molecular mechanism of neurodegenerative disease. New Jersey, Humana Press, 2001, p. 410.

CHRISTENSEN, H. \& FONNUM, F. "Uptake of glycine, GABA and glutamate by synaptic vesicles isolated from different regions of rat CNS". Neurosci Lett. 129(2): 217-220, 1991a.

CHRISTENSEN, H. \& FONNUM, F. "The ontogeny of the uptake systems for glycine, GABA and glutamate in synaptic vesicles isolated from rat spinal cord-medulla". Brain Res Dev Brain Res. 64(1-2): 155-159, $1991 \mathrm{~b}$.

COOPER, A. J. et al. "The metabolic fate of 13 N-labeled ammonia in rat brain". J Biol Chem. 254(12): 4982-4992, 1979.

COOPER, A. J. “Ammonia metabolism in mammals: interorgan relationships". Adv Exp Med Biol. 341: 21-37, 1993.

DAIKHIN, E. T. \& YUDKOFF, M. "Compartmentation of Brain Glutamate Metabolism in Neurons and Glia”. J Nutr. 130 (4S Suppl):1026S-1031S, 2000.

DEROUICHE, A. \& FROTSCHER, M. “Astroglial processes around identified glutamatergic synapses contain glutamine synthetase: evidence for transmitter degradation”. Brain Res. 552(2): 346-350, 1991.

DROGE, W. "Free radicals in the physiological control of cell function". Physiol Rev. 82(1): 47-95, 2002.

EISENBERG, D. et al. "Structure-functin relationships of glitamine synthetases". Biochim Biophys Acta. 1477(1-2): 122-145, 2000.

ERECINSKA, M. et al. "Neuronal glutamine utilization: glutamine/glutamate homeostasis in synaptosomes”. J Neurochem. 54(6): 2057-2069, 1990.

FADEEL, B.; ZHIVOTOVSKY, B. \& ORRENIUS, S. “All along the watchtower: on the regulation of apoptosis regulators". FASEB J. 13(13): 1647-1657, 1999. 
FARHY-TSELNICKER, I. \& ALLEN, N. J. "Astrocytes, neurons, synapses: a tripartite view on cortical circuit development". Neural Dev. 13(1): 7, 2018.

FAZZARI, P. et al. "Control of cortical GABA circuitry development by Nrg1 and ErbB4 signalling”. Nature. 464(7293): 1376-1380, 2010.

FERNANDES, S. P. et al. "Inactivation of astrocytic glutamine synthetase by hydrogen peroxide requires iron”. Neurosci Lett. 490: 27-30, 2011.

GONZÁLEZ, M. "Ciclo del GABA en el cerebro: su misión en la transmisión nerviosa". In: Curso monográfico sobre Neuroquímica. Madrid, Editorial de la Universidad Complutense, 1985, pp. 251-273.

HAVEL, L. S.; LI, S. \& LI, XJ. "Nuclear accumulation of polyglutamine disease proteins and neuropathology". Mol Brain. 2: 21, 2009.

HAYASHI, M. K. "Structure-function relationship of transporters in the glutamate-glutamine cycle of the central nervous system". Int J Mol Sci. 19(4): 1177, 2018.

HAYES, M. T. "Parkinson's Disease and Parkinsonism". Am J Med. 132(7): 802-807, 2019.

HERTZ, L. et al. "Astrocytes: glutamate producers for neurons". J Neurosci Res. 57(4): 417-428, 1999.

HERTZ, L. \& ROTHMAN, D. L. "Glutamine-glutamate cycle flux is similar in cultured astrocytes and brain and both glutamate production and oxidation are mainly catalyzed by aspartate aminotransferase". Biology (Basel). 6(1): 17, 2017.

HUANG, D. et al. "Glutamate-glutamine and GABA in brain of normal aged and patients with cognitive impairment”. Eur Radiol. 27(7): 2698-2705, 2017.

JAENICKE, L. \& BERSON, W. "Glutamine synthetase from pig brain: binding of adenosine triphosphate”. Hoppe Seylers Z Physiol Chem. 358(7): 883-889, 1977.

KALB, R. \& FOX, A. "Synchronized overproduction of AMPA, kainate, and NMDA glutamate receptors during human spinal cord development". J Comp Neurol. 384(2): 200-210, 1997.

KOVACEVIC, Z. \& MCGIVAN, J. D. "Mitochondrial metabolism of glutamine and glutamate and its physiological significance". Physiol Rev. 63(2): 547-605, 1983. 
KULIJEWICZ-NAWROT, M. et al. "Astrocytes and glutamate homoeostasis in Alzheimer's disease: a decrease in glutamine synthetase, but not in glutamate transporter-1, in the prefrontal cortex". ASN Neuro. 5(4): 273-282, 2013.

LE PRINCE, G. et al. "Glutamine synthetase (GS) expression is reduced in senile dementia of the Alzheimer type". Neurochem Res. 20: 859-862, 1995.

LEWERENZ, J. \& MAHER, P. "Chronic glutamate toxicity in neurodegenerative diseases-what is the evidence?”. Front Neurosci. 9: 469, 2015.

MACIEJEWSKI, P. K. \& ROTHMAN, D. L. "Proposed cycles for functional glutamate trafficking in synaptic neurotransmission". Neurochem Int. 52: 809$825,2008$.

MADEIRA, C. et al. "Elevated glutamate and glutamine levels in the cerebrospinal fluid of patients with probable Alzheimer's disease and depression". Front Psychiatry. 9: 561, 2018.

MAFFEI, A. et al. "Emerging Mechanisms Underlying Dynamics of GABAergic Synapses". J Neurosci. 37(45): 10792-10799, 2017.

MAGISTRETTI, P. J. \& ALLAMAN, I. "Lactate in the brain: from metabolic end-product to signalling molecule". Nat Rev Neurosci. 19(4): 235-249, 2018.

MARAGAKIS, N. J. \& ROTHSTEIN, J. D. "Mechanisms of disease: astrocytes in neurodegenerative disease”. Nat Clin Pract Neurol. 2(12): 679-689, 2006.

MATÉS, J. M.; PÉREZ-GÓMEZ, C. \& NÚÑEZ DE CASTRO, I. “Antioxidant enzymes and human diseases”. Clin. Biochem. 32(8): 595-603, 1999.

MAURIZI, M. R.; PINKOFSKY, H. B. \& GINSBURG, A. "ADP, chloride ion, and metal ion binding to bovine brain glutamine synthetase". Biochemistry. 26(16): 5023-5031, 1987.

MAYORQUIN, L. C. et al. "Connexin-mediated functional and metabolic coupling between astrocytes and neurons". Front Mol Neurosci. 11:118, 2018.

MCKENNA, M. et al. "Exogenous glutamate concentration regulates the metabolic fate of glutamate in astrocytes". J.Neurochem. 66(1): 386-393, 1996.

MEISTER, A. "Glutamine synthetase from mammalian tissues". Methods Enzymol. 113: 185-199, 1985. 
MEREDITH, G. E. et al. "Impaired glutamate homeostasis and programmed cell death in a chronic MPTP mouse model of Parkinson's disease". Exp Neurol. 219(1): 334-40, 2009.

MESTIKAWY, S. et al. "Characterization of an atypical member of the $\mathrm{Na}^{+}$/ $\mathrm{Cl}^{-}$-dependent transporter family: chromosomal localization and distribution in GABAergic and glutamatergic neurons in the rat brain". J Neurochem. 62: 445455, 1994.

MEUNIER, C. et al. "Astrocytes are key but indirect contributors to the development of the symptomatology and pathophysiology of Huntington's disease". Glia. 64(11): 1841-56, 2016.

MIYAKE, T. \& KITAMURA, T. "Glutamine synthetase immunoreactivity in two types of mouse brain glial cells". Brain Res. 586(1): 53-60, 1992.

ORELLANA, J. A. \& STEHBERG, J. "Hemichannels: new roles in astroglial function". Front Physiol. 5: 193, 2014.

PASCUAL, J. M. et al. "Glutamate, glutamine, and GABA as substrates for the neuronal and glial compartments after focal cerebral ischemia in rats". Stroke. 29(5): 1048-1056, 1998.

PEKNY, M. \& NILSSON, M. “Astrocyte activation and reactive gliosis". Glia. 50(4): 427-434, 2005.

PELLERIN, L. \& MAGISTRETTI, P. J. “Glutamate uptake into astrocytes stimulates aerobic glycolysis: a mechanism coupling neuronal activity to glucose utilization". Proc Natl Acad Sci. 91(22):10625-10629, 1994.

PELLERIN, L. \& MAGISTRETTI, P. J. "Sweet sixteen for ANLS”. J Cereb Blood Flow Metab. 32(7): 1152-1166, 2012.

PENG, L.; SCHOUSBOE, A. \& HERTZ, L. "Utilization of a-ketoglutarate as a precursor for transmitter glutamate in cultured cerebellar granule cells". Neurochem Res. 16(1): 29-34, 1991.

PENG, L.; ZHANG, X. \& HERTZ, L. "High extracellular potassium concentrations stimulate oxidative metabolism in a glutamatergic neuronal culture and glycolisis in cultured astrocytes, but have no stimulatory effect in GABAergic neuronal culture". Brain Res. 663(1): 168-172, 1994. 
PLAITAKIS, A. \& SHASHIDHARAN, P. “Glutamate transport and metabolism in dopaminergic neurons of substantia nigra: implications for the pathogenesis of Parkinson's disease". J Neurol. 247(Suppl 2): 1125-1135, 2000.

POITRY, S. et al. "Mechanisms of glutamate metabolic signaling in retinal glial Muller cells". J Neurosci. 20(5): 1809-1821, 2000.

PROCTER, A. W. et al. "Evidence of glutamatergic denervation and possible abnormal metabolism in Alzheimer's disease". J Neurochem. 50(3): 790-802, 1988.

QUERFURTH, H. W. \& LAFERLA, F. M. “Alzheimer's disease”. $N$ Engl J Med. 362: 329-344, 2010.

RAMAHAROBANDRO, N. et al. "Glutamine and glutamate transport in cultured neuronal and glial cells". Brain Res. 244(1): 113-121, 1982.

ROBINSON, S. R. "Changes in the cellular distribution of glutamine synthetase in Alzheimer's disease". J Neurosci Res. 66(5): 972-980, 2001.

RODRIGO, R. \& FELIPO, V. "Control of brain glutamine synthesis by NMDA receptors". Frontiers in Bioscience. 12: 883-890, 2007.

SAHLENDER, D. A.; SAVTCHOUK, I. \& VOLTERRA, A. "What do we know about gliotransmitter release from astrocytes?". Philos Trans $R$ Soc Lond B Biol Sci. 369(1654): 20130592, 2014.

SCHOUSBOE, A. et al. "Glutamate and glutamine metabolism and compartimentation in astrocytes”. Dev Neurosci. 15 (3-5): 359-366, 1993.

SHABEL, J. et al. "GABA/glutamate co-release controls habenula output and is modified by antidepressant treatment". Science. 345(6203): 1494-1498, 2014.

SELLSTROM, A. \& HAMBERGER, A. "Potassium-stimulated g-aminobutiric acid release from neurons and glia”. Brain Res. 119: 189-198, 1977.

SHEN, J. et al. "Determination of the rate of the glutamate/glutamine cycle in the human brain by in vivo 13C NMR". Proc Natl Acad Sci. 96(14): 82358240, 1999.

SIDORYK-WEGRZYNOWICZ, M. \& ASCHNER, M. "Manganese toxicity in the central nervous system: the glutamine/glutamate- $\gamma$-aminobutyric acid cycle". J Intern Med. 273(5): 466-477, 2013. 
SIMÃO, D. et al. "Functional metabolic interactions of human neuron-astrocyte 3D in vitro networks". Sci Rep. 6: 33285, 2016.

SMITH, Q. R. et al. "Kinetics of neutral amino acid transport across the blood-brain-barrier". J. Neurochem. 49(5): 1651-1658, 1987.

STANLEY, B. \& PRUSINER, M. D. "Disorders of glutamate: metabolism and neurological dysfunction”. Ann Rew Med. 32: 521-542, 1981.

SUÁREZ, I. et al. "Reduced glial fibrillary acidic protein and glutamine synthetase expression in astrocytes and Bergmann glial cells in the rat cerebellum caused by delta(9)-tetrahydrocannabinol administration during development". Dev Neurosci. 24(4): 300-312, 2002.

SVENNEBY, G. \& TORGNER, I. A. "Localization and function of glutamine synthetase and glutaminase". Biochem Soc Trans. 15(2): 213-215, 1987.

TANOVIĆ, A. \& ALFARO, A. "Glutamate-related excitotoxicity neuroprotection with memantine, an uncompetitive antagonist of NMDA-glutamate receptor, in Alzheimer's disease and vascular dementia". Rev Neurol. 42(10): 607-616, 2006.

TUMANI, H. et al. "Glutamine synthetase in cerebrospinal fluid, serum, and brain: a diagnostic marker for Alzheimer disease?”. Arch. Neurol. 56: 12411246, 1999.

VILLEMAGNE, V. L. et al. "Amyloid $\beta$ deposition, neurodegeneration, and cognitive decline in sporadic Alzheimer's disease: a prospective cohort study". Lancet Neurol. 2(4): 357-367, 2013.

VOLTERRA, A. \& MELDOLESI, J. “Astrocytes, from brain glue to communication elements: the revolution continues". Nat Rev Neurosci. 6(8): 626-640, 2005.

WALTON, H. S. \& DODD, P. R. “Glutamate-glutamine cycling in Alzheimer's disease”. Neurochem Int. 50(7-8): 1052-1066, 2007.

WELBOURNE, T. et al. "The glutamine/glutamate couplet and cellular function". News Physiol Sci. 16: 157-160, 2001.

YOO, J. H. et al. "Ventral tegmental area glutamate neurons co-release GABA and promote positive reinforcement". Nat Commun. 7: 13697, 2016. 
ZHANG, Y. et al. "Recent advance in the relationship between excitatory amino acid transporters and Parkinson's disease". Neural Plast. 2016: 8941327, 2016. ZIMMERMANN, J.; HERMAN, M. A. \& ROSENMUND, C. "Co-release of glutamate and GABA from single vesicles in GABAergic neurons exogenously expressing VGLUT3”. Front Synaptic Neurosci. 7: 16, 2015. 
